\title{
Effects of Supplemental Lighting with Light-Emitting Diodes (LEDs) on Tomato Yield and Quality of Single-Truss Tomato Plants Grown at High Planting Density
}

\author{
Na Lu', Toru Maruo', Masahumi JohKan'1, Masaaki Hohjo², Satoru Tsukagoshi², \\ Yoshikazu ITO $^{2}$, Takuya IChIMURA ${ }^{3}$ and Yutaka SHINOHARA ${ }^{1}$ \\ 'Graduate School of Horticulture, Chiba University, Matsudo, Chiba 271-8510, Japan \\ ${ }^{2}$ Center for Environment, Health and Field Sciences, Chiba University, Kashiwa, Chiba 277-0882, Japan \\ ${ }^{3}$ Development Group of Industrial Film Development Center, Mitsubishi Plastics, Inc., \\ Nagoya, Aichi 453-0862, Japan
}

(Received November 18, 2011; Accepted January 26, 2012)

\begin{abstract}
In the present study, we investigated the effects of supplemental lighting (SL) with white, red, and blue light-emitting diodes (LEDs) on the yield and quality of tomato grown under the single-truss tomato production system (STTPS). SL was applied for 28 days during the rapid fruit development stage. Based on the same power consumption, the light treatments with the white and red LEDs increased the fresh yield of tomato by 12 and 14\%, and the dry yield by 16 and $14 \%$, compared with the control (without SL), respectively. Based on the unit photons emitted, the white LEDs showed high efficiency as the red LEDs in increasing tomato yield, followed by the blue ones. The results were probably due to the white LEDs that contained more than $50 \%$ of green light characterized by high penetration into the canopy. The sugar and ascorbic acid contents were not affected by SL from the LEDs. These results indicated that the white and red LEDs were effective in enhancing tomato yield and, in particular, the white LEDs with a combination of red, blue, and abundent green light would be more suitable to the use of STTPS at a high plant density.
\end{abstract}

Keywords : LEDs, spectral distribution, supplemental lighting, tomato

\section{INTRODUCTION}

The single-truss tomato production system (STTPS) is a promising cultivation method for plant factory to achieve uninterrupted year-round, predictable production of uniform-quality tomatoes with efficient use of resources and labor (Giacomelli et al., 1994; McAvoy, 1984; McAvoy et al., 1989a; Okano et al., 2001; Ting et al., 1993). This system also has the advantage of automation to simplify management, by using movable benches to effectively utilize greenhouse space, and for prompt change of plants in case of accident, etc. Moreover, the STTPS showed the potential for achieving a high annual yield of more than $50 \mathrm{~kg} \cdot \mathrm{m}^{-2}$ by increasing the plant density to 10 plants . $\mathrm{m}^{-2}$, and the yield per unit area could be further enhanced at a higher plant density (Kobayashi, 1997; 1999). However, the fruit weight per plant decreased with the increase of plant density due to the light environmental degradation associated with the mutual shading at a high plant density.

Light is one of the main factors limiting the yield of tomato plants grown under the STTPS

Corresponding author: Masahumi Johkan, fax : +81-4-7308-8807, e-mail : johkan@faculty.chiba-u.jp 


\section{N. LU ET AL.}

at a high plant density (Kobayashi, 1999). Inter-lighting was considered to be an effective method to increase tomato yield and to improve the quality of tomato fruits with the STTPS at a high plant density and the application of inter-lighting by fluorescent lamps to the tomato plants grown under the STTPS at the rapid fruit development stage increased the yield and sugar content of tomato (Lu et al., 2012). Their results also indicated that the tomato yield may increase with the increase of the amount of supplemented light. Besides the light amount (light intensity $\times$ photoperiod), the light quality also is an important light factor that affects plant growth (Goto, 2003; Massa et al, 2008). Hanyu and Shoji (2000) demonstrated that increased fractions of red or blue light at the same photosynthetic photon flux (PPF) provided by fluorescent lamps enhanced the total dry matter production and affected the dry matter distribution in kidney bean. Increase of red light application resulted in the increase of the leaf area and stem length, while the increase of blue light resulted in a significant inhibition of stem extension and thickening of leaf. Cosgrove (1981) reported that blue light reduced cell expansion and thus inhibited leaf growth and stem elongation in cucumber, sunflower, azuki bean, zucchini, pea, and mung bean seedlings. Green light is commonly considered to be least effective in plant growth, as most plants reflect green light and absorb less green light relative to red and blue light. However, green light mixed with strong white light promoted photosynthesis more effectively than red light in sunflower leaves (Terashima et al., 2009) and only green light at a high PPF was also able to secure normal growth of red leaf lettuce (Johkan et al., 2012). Moreover, green light can penetrate into the plant canopy more deeply than red or blue light to contribute to the photosynthesis of lower leaves and to the enhancement of plant growth (Klein, 1992; Smith, 1993; Kim, 2004). Thus, the use of a high planting density in the STTPS might be benefit from the application of red light and blue light combined with green light.

Growth of tomato at a high plant density combined with moving benches in the STTPS can maximize the space utilization efficiency. Therefore, the weight of the lamps should be light for mobility, their life time should be long to avoid periodical replacement, and the emitting surface should be relatively cool to avoid burning of leaves. Light-emitting diodes (LEDs) are characterized by a long life time, cool emitting surface, low power consumption and wavelength specificity. However, the commercialized high-brightness LED lighting units are often heavy compared with the fluorescent lamps used in the STTPS. Since the moving bench system in the STTPS was tailored to fluorescent lamps (Tube type, $125 \times 6.5 \mathrm{~cm}$ ), the light LED units with a fluorescent lamp shape need to be developed for this system. As the technology of LED continues to improve, these types of LED units would be more suitable for providing supplemental lighting within the canopy in the STTPS at a high plant density. In the present study, we tested three kinds of experimental lighting units, namely white, red and blue LEDs to evaluate their performance in optimization of the STTPS. They were light with a fluorescent lamp shape but differed in the light distribution pattern. The objectives of the present study were to examine the effects of the different LED lamps on the yield and quality of tomato grown under the STTPS at a high plant density based on the same power consumption, and to reveal the efficiency of these lighting units in the increase of tomato yield based on the unit photons emitted.

\section{MATERIALS AND METHODS}

\section{Plant materials and growth conditions}

Tomato (Solanum lycopersicum L., cv. Momotaro Natsumi, Takii Seed Co., Ltd., Japan) seeds were sown in 128-cell plug trays filled with commercial substrate (Tanebaido 1, Sumitomo Forestry Co., Ltd., Aichi, Japan) on August 9, 2010. After germination in darkness at $28^{\circ} \mathrm{C}$, the seedlings were grown in a temperature-controlled chamber equipped with fluorescent lamps (Nae Terrace, MKV Dream Co., Ltd., Tsukubamirai, Japan). The PPF on the surface of the tray $(25 \mathrm{~cm}$ distance from the lamp) was $360 \pm 10 \mu \mathrm{mol} \cdot \mathrm{m}^{-2} \cdot \mathrm{s}^{-1}$. The day/night temperature range was $23 /$ 
$17^{\circ} \mathrm{C}$. On September 3, the seedlings were transplanted to $9 \mathrm{~cm}$ diameter pots filled with granulated rockwool (66R, Nitto Boseki Co., Ltd., Tokyo, Japan). NS-oriented movable benches (bench size: $4 \times 0.15 \mathrm{~m}$ ), consisting of 18 rows, were placed in a greenhouse and used in the experiment. The potted seedlings were set on movable benches in rows $10 \mathrm{~cm}$ apart and at a $70 \mathrm{~cm}$ interval between rows at a plant density of 14.3 plants $\cdot \mathrm{m}^{-2}$ in a greenhouse. Half-strength of Enshi formula nutrient solution $\left(\mathrm{NO}_{3}-\mathrm{N} 8, \mathrm{PO}_{4}-\mathrm{P} 2, \mathrm{~K} 4, \mathrm{Ca} 4, \mathrm{Mg} 2, \mathrm{SO}_{4} 2 \mathrm{me} \cdot \mathrm{L}^{-1}\right)$, at an electrical conductivity (EC) of $1.2 \mathrm{dS} \cdot \mathrm{m}^{-1}$ was supplied to the tomato plants by using a drip irrigation system to maintain $20-30 \%$ drainage. The drip irrigation system was activated when cumulative solar radiation reached a value of $1 \mathrm{MJ} \cdot \mathrm{m}^{-2}$. Pest and disease control was in accordance with commercial practices. The plants were pinched at the first truss above 3 remaining leaves, on September 26, at the anthesis stage of the first truss.

\section{Lighting treatments}

Four groups of plants were subjected to lighting with three kinds of LEDs (provided by MKV Dream Co., Ltd., Tsukubamirai, Japan): white, red and blue LEDs, respectively, in addition to the control plants which were not subjected to supplemental lighting (SL). Each LED unit had the same power consumption of $18 \mathrm{~W}$. The size and arrangement of diodes of the LED units are shown in Fig. 1 (a). Figure 1 (b) shows the spectral distribution scans taken from 400 to $700 \mathrm{~nm}$ at $1 \mathrm{~nm}$ step with a spectroradiometer (MS-720, EKO Instruments Co., Ltd., Tokyo, Japan). Based on the spectroradiometric data for each light treatment, the fraction of blue, green and red light of each LED unit and the PPF at different distances from the unit were determined (Table 1). The LEDs were horizontally hung at a distance of $25 \mathrm{~cm}$ from the plant stem on one side at the position equivalent to the middle height of the plants (we used the same SL method described by Lu et al. (2012), by replacing the light sources in the present experiment). One LED unit illuminated 10
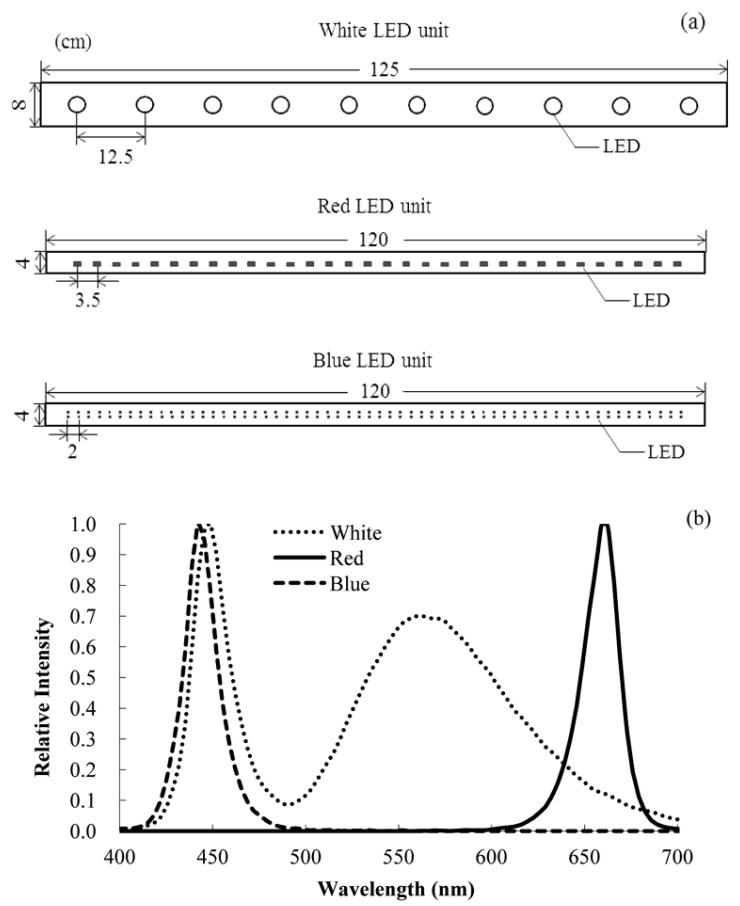

Fig. 1 Arrangement of LEDs in white, red, and blue LED units (a) and spectrum of these lights (b). The relative spectral photon flux of each LED lighting unit was normalized to 1 at $448 \mathrm{~nm}$ (white), $660 \mathrm{~nm}$ (red), $442 \mathrm{~nm}$ (blue), respectively. 


\section{N. LU ET AL.}

Table 1 Spectral data for white, red and blue light-emitting diodes (LEDs).

\begin{tabular}{|c|c|c|c|}
\hline \multirow[b]{2}{*}{ Parameter } & \multicolumn{3}{|c|}{ Light source } \\
\hline & White LEDs & Red LEDs & Blue LEDs \\
\hline \multicolumn{4}{|l|}{ Fraction $(\%)$} \\
\hline Blue $(400-500 \mathrm{~nm})$ & 24.8 & 0 & 100 \\
\hline Green $(500-600 \mathrm{~nm})$ & 54.3 & 0 & 0 \\
\hline $\operatorname{Red}\left(600^{-700 \mathrm{~nm})}\right.$ & 20.9 & 100 & 0 \\
\hline \multicolumn{4}{|l|}{ Photon flux ${ }^{2}\left(\mu \mathrm{mol} \cdot \mathrm{m}^{-2} \cdot \mathrm{s}^{-1}\right)$} \\
\hline $5 \mathrm{~cm}$ distance from LEDs & 129 & 143 & 70 \\
\hline $25 \mathrm{~cm}$ distance from LEDs & 28 & 34 & 16 \\
\hline $\begin{array}{l}\text { Amount of daily received photons by } \\
\text { one plant } \mathrm{t}^{\mathrm{y}}\left(\mathrm{mol} \cdot \text { plant }^{-1} \cdot \mathrm{d}^{-1}\right)\end{array}$ & 0.079 & 0.1 & 0.034 \\
\hline
\end{tabular}

${ }^{z}$ The LED unit was located at a distance of $25 \mathrm{~cm}$ from the stem of tomato plants, the nearest leaf tip actually lay at a distance of $5 \mathrm{~cm}$ from the LED unit.

${ }^{y}$ The supplemental lighting was applied at the $1 \mathrm{~m}$ height and $0.1 \mathrm{~m}$ width of tomato plants. The amount of daily received photons by one plant was calculated as those on the plane (1 $\mathrm{m}$ in height and $0.1 \mathrm{~m}$ in width) at $25 \mathrm{~cm}$ distance from each LED unit. The plane was divided into the small squares which were $0.05 \mathrm{~m}$ in height and width, then the amount of daily received photons by one plant (mol. plant $\left.^{-1} \cdot \mathrm{d}^{-1}\right)$ was calculated as the sum of the PPF $\left(\mu \mathrm{mol} \cdot \mathrm{m}^{-2} \cdot \mathrm{s}^{-1}\right)$ which was measured at the center of each square multiplied by the area of each square $\left(0.0025 \mathrm{~m}^{2}\right)$, multiplied by the lighting time $\left(3,600 \mathrm{~s}\right.$ for $1 \mathrm{~h}$ and $16 \mathrm{~h}$ per day), and divided by $10^{6}$ ( $\mu$ mol to mol) (it was considered that most of the photons from the LED unit were intercepted by plants because the transmitted light intensity on the other side of the plants was close to 0 ).

plants. The present experiment was conducted in the greenhouse in which we tried to provide same PPFs to the leaves closest to the LEDs by adjusting the distance from the LEDs, but the pathway space for each treatment became different (the lamp installing system was fixed, only the benches could be moved). The different arrangement patterns of diodes also made the distributions of light emitted by LEDs different and the light intensity did not subtract by certain amount with the same increase of distance apart from each LED unit (Table 1). As the LED units were fixed at a specified location and the positions of leaves of different plants were different, the leaves of all the plants could not receive the same PPFs in practical application. Thus, we calculated the increase of tomato yield enhanced by unit photons to estimate the effect of light quality on the tomato yield. Tomato plants were subjected to lighting from the LEDs for $16 \mathrm{~h}$ per day $(5: 00-21: 00)$. The lighting was supplied to all the groups from October 15 (18 days after anthesis) to November 11 for 28 days, at the rapid fruit development stage from fruit-set to mature-green (Lu et al., 2012). Each treatment (white, red and the blue LEDs) consisted of 20 plants was replicated twice and finally data was recorded on 12 plants.

\section{Measurements}

The fruits were harvested from November 28 to December 3, and the fruit fresh and dry weights were measured. The ascorbic acid content of tomato fruits was determined using RQ Flex plus (Merck Co., Ltd., Darmstadt, Germany) and the sugar content was determined using a refractometer (IPR-101, Atago Co., Ltd., Tokyo, Japan). For determining the relationship between the fruit diameter and the fruit fresh weight $(\mathrm{FFW})$, the fruits from the tomato plants which were not exposed to SL were picked every 3 days and the fruit diameter (mm) and the FFW (g) were measured. The regression equation was as follows: $y=0.0002 x^{3}+0.0318 x^{2}-1.2524 x+15.482$, with $\mathrm{R}^{2}=0.9924(\mathrm{y}=\mathrm{FFW}$ and $\mathrm{x}=$ fruit diameter $)$. The fruit diameter of the control and SL-treated plants was measured every 4 days from fruit sizing stage to harvest, and the FFW was estimated based on the equation listed above. The fruit growth rate (FGR) of tomato was calculated as $\mathrm{FGR}=\left(\mathrm{W}_{2}-\mathrm{W}_{1}\right) /\left(\mathrm{T}_{2}-\mathrm{T}_{1}\right)$, where $\mathrm{W}_{1}$ was the FFW at the first sampling time point $\left(\mathrm{T}_{1}\right)$ and $\mathrm{W}_{2}$ at the second sampling time point $\left(\mathrm{T}_{2}\right)$. For each lighting group, the PPF distributed within the 


\section{LIGHT QUALITY AND TOMATO}

canopy was measured in the absence of natural daylight with a quantum sensor (LI-190SA, Li-Cor Inc., Lincoln, NE, USA) on October 25, (28 days after anthesis). Through the plants from the lighting side to the other side, 5 vertical planes were divided at $10 \mathrm{~cm}$ intervals, and 20 points at a distance of every $5 \mathrm{~cm}$ from the top of plant to the lowest leaf were measured on each vertical plane. Then the light penetration was calculated as the sum of PPF on a certain vertical plane with plants, divided by the sum of PPF on the vertical plane without plants. Sunlight intensity outside of the greenhouse was measured with the quantum sensor, which was connected to a data logger (CR1000, Campbell Scientific, INC., USA) during the experimental period and the daily accumulated solar radiation was calculated. Spectral distribution of solar radiation above, within, and below the closed canopy of tomato plants was measured with the spectroradiometer on December 20, 2011, a cloudless day. Transmittance of all the LEDs light through individual fully expanded tomato leaves was measured with the same instrument on the same day.

\section{RESULTS}

\section{Effects of supplemental lighting from different LEDs on tomato yield and quality based on} the same power consumption

The fresh yield of the tomato plants subjected to lighting with white and red LEDs significantly increased by 12 and $14 \%$, and the dry yield significantly increased by 16 and $14 \%$, compared with the control, respectively (Table 2). The significant increase in the fruit fresh weight per plant in the white and red LED groups occurred from 31 days after anthesis, compared with the control (Fig. 2). However, SL provided by blue LEDs did not significantly affect the fresh and dry yields of tomato and the fruit fresh weight during the fruit development. The sugar and ascorbic acid con-

Table 2 Effects of lighting with different LEDs on the yield and quality of tomato fruits grown under the STTPS at a high plant density.

\begin{tabular}{lcccc}
\hline Treatment & $\begin{array}{c}\text { Fresh yield } \\
\text { per plant } \\
(\mathrm{g})\end{array}$ & $\begin{array}{c}\text { Dry yield } \\
\text { per plant } \\
(\mathrm{g})\end{array}$ & $\begin{array}{c}\text { Sugar } \\
\text { content } \\
(\text { Brix } \%)\end{array}$ & $\begin{array}{c}\text { Ascorbic } \\
\text { acid content } \\
\left(\mathrm{mg} \cdot \mathrm{kgFW}^{-1}\right)\end{array}$ \\
\hline Control & $388 \mathrm{~b}^{\mathrm{z}}$ & $22.7 \mathrm{~b}$ & $5.8 \mathrm{a}$ & $121 \mathrm{a}$ \\
White LEDs & $435 \mathrm{a}$ & $26.3 \mathrm{a}$ & $6.1 \mathrm{a}$ & $134 \mathrm{a}$ \\
Red LEDs & $441 \mathrm{a}$ & $25.8 \mathrm{a}$ & $6.0 \mathrm{a}$ & $118 \mathrm{a}$ \\
Blue LEDs & $404 \mathrm{~b}$ & $23.6 \mathrm{~b}$ & $5.8 \mathrm{a}$ & $118 \mathrm{a}$ \\
\hline
\end{tabular}

${ }^{2}$ Different letters represent significant differences according to Tukey's multiple range test at the 5\% level $(n=12)$.

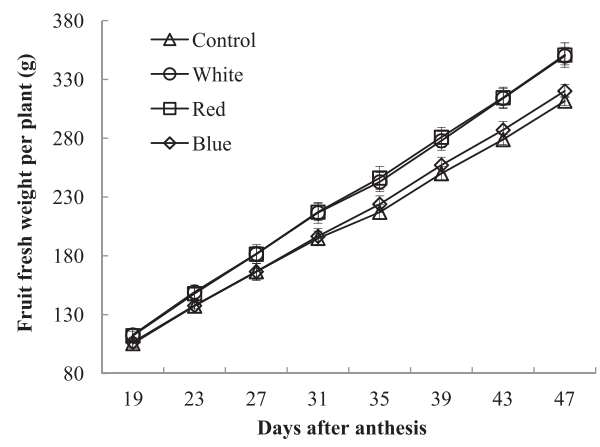

Fig. 2 Variation of cumulative growth of tomato fruit subjected or not subjected to supplemental lighting $(n=6)$. Fruit fresh weight $(F F W)$ was calculated by $y=0.0002 x^{3}+0.0318 x^{2}-1.2524 x+15.482$, with $\mathrm{R}^{2}=0.9924(\mathrm{y}=\mathrm{FFW}$ and $\mathrm{x}=$ fruit diameter $)$. 


\section{N. LU ET AL.}

tents of tomato fruits did not significantly differ among the respective treatments.

2. Effect of unit light amount from different LEDs on the increase of tomato fruit fresh weight

To investigate the effect of the light quality on the growth of tomato fruit, the increase of the tomato fruit fresh weight induced by unit photons emitted, was calculated in the present study (Fig. 3). The slope which indicates the efficiency of SL in increasing the fruit fresh weight, and is defined as the increase of the fruit fresh weight in response to $1 \mathrm{~mol}$ photons provided by SL. The slopes were in the order of white (17.7), red (14.9), and blue (9.1) LEDs in the present experiment. Thus, for the same unit photons emitted, application of SL with white LEDs was the most efficient in increasing the fruit fresh weight, followed by the red LEDs, while the lowest efficiency was recorded with the blue LEDs.

\section{Spectral distribution and light penetration into the canopy}

The pattern of spectral distribution within the canopy was similar to that transimitted through an individual fully expanded leaf. The results indicated that tomato leaves transmitted little blue

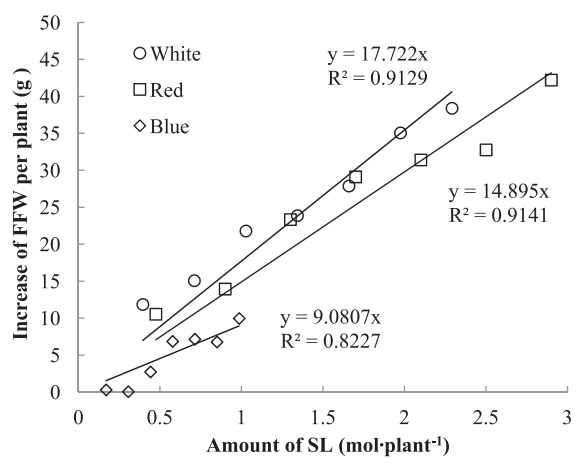

Fig. 3 Increase of fruit fresh weight (FFW) per plant plotted against the amount of supplemental lighting (SL) applied to one plant. Increase of fruit fresh weight was calculated by subtracting FFW of control plants from the FFW of plants with supplemental lighting (SL). The amount of the SL (mol) applied to one plant was calculated as the amount of daily received photons by one plant (Table 1) multiplied by days of SL application.

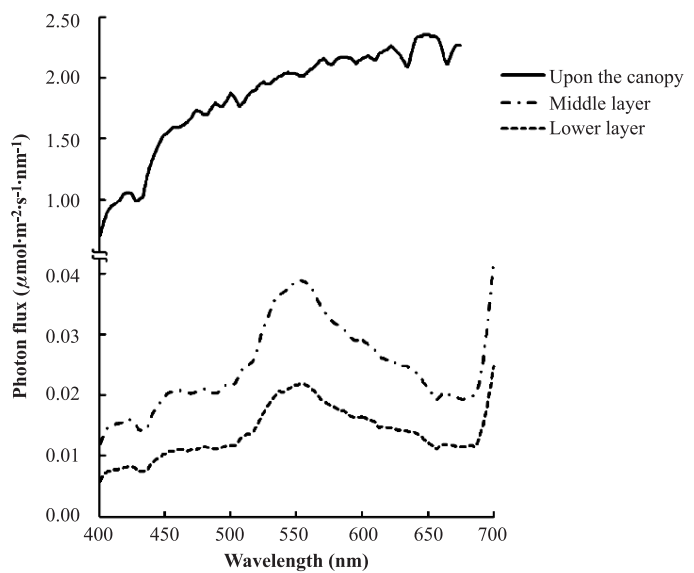

Fig. 4 Spectral distribution of solar radiation above (upon the canopy, on the top of tomato plants), within (middle layer, $30 \mathrm{~cm}$ below the top), and below (lower layer, $60 \mathrm{~cm}$ below the top) the closed tomato canopy. (Data were collected on December 20, 2011, a cloudless day). 


\section{LIGHT QUALITY AND TOMATO}

and red light but were relatively transparent to green light (500-600 nm) (Fig. 4 and Fig. 5). The light penetration of the white LEDs was 52 and $16^{-11 \%}$ on the vertical plane at a distance of 10 and $20^{-50} \mathrm{~cm}$ from the LED unit, respectively (Fig. 6). In contrast, the light penetration of the red and blue LEDs was calculated as 13 and $15 \%$ on the vertical plane at a distance of $10 \mathrm{~cm}$ from the LED unit, respectively. At a distance of $20-50 \mathrm{~cm}$ from the LED unit, the light penetration of the red and blue LEDs further decreased to $6^{-3}$ and 9-4\%, respectively. Therefore, more than half of the light from white LEDs was able to penetrate into the canopy, while more than $80 \%$ of the light from red and blue LEDs was intercepted by the surface leaves within a $10 \mathrm{~cm}$ depth of the vertical plane.

\section{Relationship between fruit growth rate and level of solar radiation}

The fruit growth rate (FGR) showed almost the same changes as the variations of the solar ra-
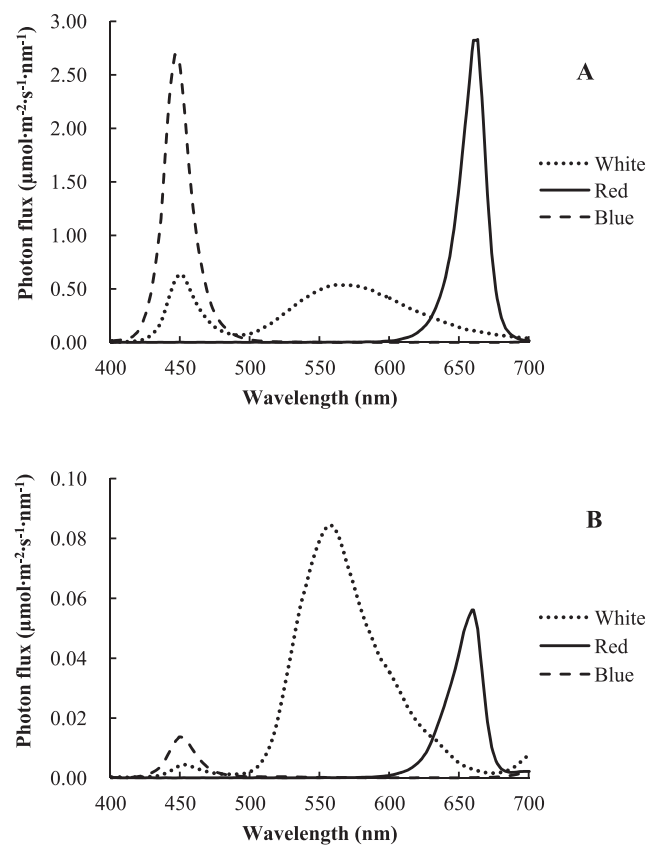

Fig. 5 Spectral distribution of white, red, and blue light before (A) and after (B) through an individual fully expanded tomato leaf. Spectra were recorded at the point of $70 \mu \mathrm{mol} \cdot \mathrm{m}^{-2} \cdot \mathrm{s}^{-1}$ in PPF with a spectroradiometer at night.

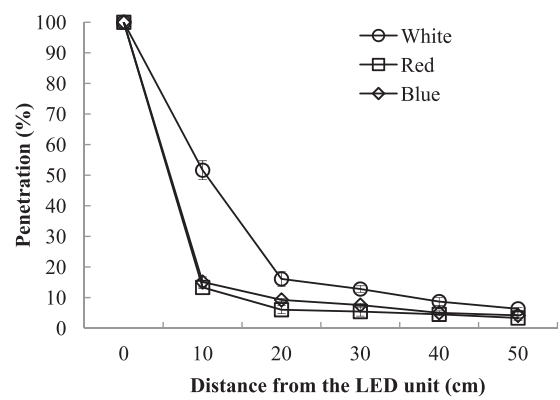

Fig. 6 Penetration (\%) of light from different LEDs into the canopy in the STTPS at a high plant density. The light penetration was calculated as the sum of PPF (photosynthetic photon flux) on a certain vertical plane with plants, divided by the sum of PPF on the vertical plane without plants $(n=5)$. 


\section{N. LU ET AL.}

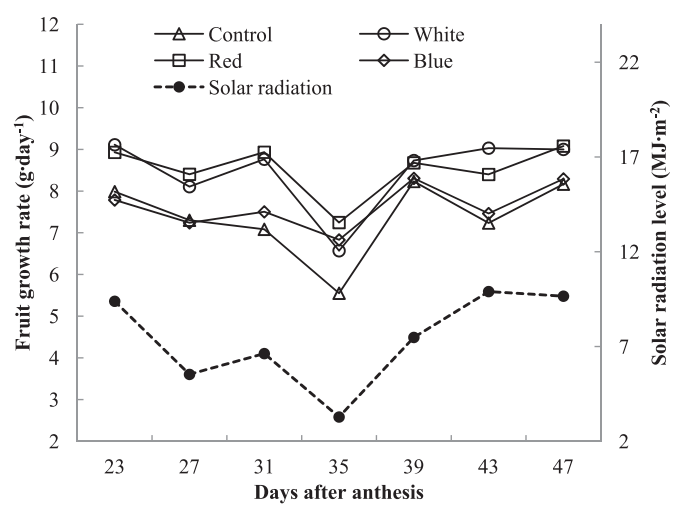

Fig. 7 Time course of fruit growth rate and solar radiation level over experimental period. The fruit growth rate $(\mathrm{FGR})$ of tomato was calculated as $\mathrm{FGR}=\left(\mathrm{W}_{2}-\mathrm{W}_{1}\right) /\left(\mathrm{T}_{2}-\mathrm{T}_{1}\right)$, where $\mathrm{W}_{1}$ was the fruit fresh weight at the first sampling time point $\left(T_{1}\right)$ and $W_{2}$ at the second sampling time point $\left(T_{2}\right)$. Sunlight intensity was measured with quantum sensor, which was connected to a data logger and the average daily accumulated solar radiation was calculated.

diation level (Fig. 7). The FGR in the white and red LED groups was higher than that in the control after 4 days (19 days after anthesis) of SL application. The FGR in the blue LED group increased when the solar radiation level was low (32-35 days after anthesis), but was not affected at other times, compared with the control. The FGR in the white LED group was higher when the solar radiation level was high, and lower when the solar radiation level was low, compared with that in the red LED group. In other words, the performance of the white LEDs was higher than that of the red and blue LEDs when the solar radiation was high, while the opposite performance was recorded when the solar radiation was low.

\section{DISCUSSION}

It was reported that the yield of tomato increased with the increase in the amount of light received from anthesis to harvest (McAvoy et al., 1989b). When the light level on the top of the canopy or within the canopy was low, application of SL at the top of the canopy or within the canopy enhanced the yield of tomato and other species (Rodriguez and Lambeth, 1975; Grimstad, 1987; McAvoy and Janes, 1989; Hovi et al., 2004; Pettersen et al., 2010). SL could increase the leaf photosynthetic rate and then increase the assimilate supply to the fruits (McAvoy and Janes, 1989; Pettersen et al., 2010). In the present study, the results were in agreement with the findings of these researchers. However, the increase of tomato yield varied with the use of different LEDs. Based on the same power consumption, the final yield of tomato significantly increased by SL when white and red LEDs were used but was not affected by the blue LEDs (Table 2).

In general, plant leaves readily absorb red and blue light, and the combination of red and blue light was reported to be an effective lighting source in the production of many crops (Brown et al., 1995; Goins, 2002; Goins et al., 1997; Goins and Yorio, 2000; Yorio et al., 2001; Ohashi-Kaneko et al., 2007; Johkan et al., 2010; Samuoliene et al., 2011). The efficiency (slope) of white LEDs (17.7) was higher than the red LEDs (14.9) in increasing tomato fresh fruit weight, based on the same amount of light emitted (Fig. 3). The white LED light consisted of a mixture of red, blue and green light and more than $50 \%$ of the total light was comprised of green light that could penetrate into the plant canopy more deeply than the red or blue light (Fig. 4, 5 and Fig. 6). In several studies, it was reported that the addition of green light combined with red and blue light from LEDs enhanced plant growth, because leaves in the lower canopy were able to use the transmitted green 
light for photosynthesis (Klein, 1992; Smith, 1993; Kim, 2004). Johkan et al. (2012) reported that the use of green light ( $\geqslant$ PPF 300) alone enabled to achieve normal growth in the lettuce plants, in the same way as fluorescent lamps. On the other hand, the amount of solar light reaching the leaves of tomato plants decreased rapidly with the depth of the canopy at a high plant density and the inner leaves hardly contributed to carbon gain and led to net respiratory carbon losses. Thus transmitted green light may enhance the photosynthesis and offset respiration of inner leaves in the canopy.

The fruit growth rate (FGR) was affected by the solar radiation level and the type of LEDs used (Fig. 7). In all the treatments, the lowest FGR was observed when the solar radiation level was low (32-35 days after anthesis), and at that time, SL with red LEDs showed a higher efficiency in FGR than that with white LEDs. However, when the solar radiation level was high (40-43 days after anthesis), SL with white LEDs showed a higher efficiency in FGR than that with red LEDs. Terashima et al. (2009) reported that green light combined with strong white light could be absorbed by the chloroplasts located in the lower layers of sunflower leaves and promoted leaf photosynthesis more efficiently than red light. These results indicated that the combination of additional light from solar radiation and white LED units may enable green light to achieve a high efficientcy in accelerating production in the STTPS at a high plant density (Fig. 4 and Fig. 5). Therefore, SL with white and red LEDs was effective in stimulating the growth of tomato fruits, especially white LEDs at a high solar radiation level and red LEDs at a low solar radiation level.

The results obtained with the blue LED treatment were ascribed to the relative low light intensity of blue LED lighting unit emission (Table 1), as well as to the low photosynthetic efficiency of blue light, compared with red light (Goto, 2003). The lowest efficiency of blue light in increasing the fruit fresh weight of tomato was also found in the present study (Fig. 3). Menard et al. (2006) reported that the introdution of $16 \mu \mathrm{mol} \cdot \mathrm{m}^{-2} \cdot \mathrm{s}^{-1}$ of blue light inside the canopy was not useful for tomato yield. In addition, the leaves of the plant produced polyphenols in order to prevent short-wavelength (ultraviolet or blue) radiation damage. Johkan et al. (2010) reported that polyphenol contents and the total antioxidant status were higher in lettuce seedlings treated with LEDs emitting blue light than in those treated with fluorescent light. Accordingly, the supplementary blue light was presumably used to produce secondary compounds and biomass for selfprotection of leaf rather than for the transport of assimilates to fruits.

In the present experiment, the sugar content did not vary among the respective treatments (Table 2). In our previous experiment, at the same tomato development stage as that in the present experiment, the use of SL from fluorescent lamps significantly increased the sugar content. This result may be related to the received amount of light from fluorescent lamp $\left(0.38 \mathrm{~mol} \cdot \mathrm{plant}^{-1}\right.$. $\mathrm{d}^{-1}$ ) was about 4 times higher than that of the red and white LED lighting units used in the present study (Table 1) because light exerted a beneficial effect on the sugar content of tomato (Gautier et al., 2008). The content of ascorbic acid is possibly affected by blue light that plays an important role in the regulation of secondary metabolites (Awad et al., 2001; Ebisawa et al., 2008; Lefsrud et al., 2008; Stutte et al., 2009; Hogewoning et al., 2010; Johkan et al., 2010; Kojima et al., 2010). However, the ascorbic acid content of the tomato fruits was also not affected by the light treatments in the present study (Table 2). In other plant species, blue light increased the ascorbic acid content (Lester, 2006; Ohashi-Kaneko et al., 2007). In tomato, Driever et al. (2011) reported that the ap-

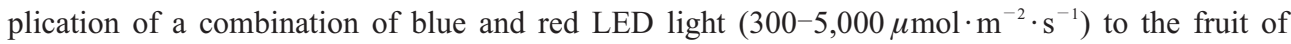
cherry tomato significantly increased the ascorbic acid content. Gautier et al. (2009) indicated that ascorbate synthesis and metabolism in fruits were significantly affected by fruit irradiance but not appreciably by leaf irradiance. In our study, the fruit irradiance by SL is likely to be low because the SL was focused on the lower leaves in the canopy, therefore, the SL did not significantly affect the ascorbic acid content.

In conclusion, the tomato yield was significantly enhanced by SL with white and red LEDs to 


\section{N. LU ET AL.}

the lower leaves of tomato plants grown under the STTPS at a high plant density. Based on the uint photons emitted, the white LEDs showed high efficiency in increasing tomato yield (especially when solar radiation level was high), presumably because of the high penetration of green light. However, the sugar and ascorbic acid contents were not affected by SL from different LEDs. These results indicated that the use of white LEDs with a combination of red, blue, and a large amount of green light would be suitable for STTPS at a high plant density.

Considerable commercial interest has been directed toward the production of white LED lighting units. Therefore, low-cost white LED lighting units could be more readily available commercially than red and blue ones. Further studies need to be carried out to assess the effects of the light quality on tomato plant growth when LED units with a high light intensity and the same light distribution pattern are used. It is expected that a LED lighting unit with high photoelectric conversion efficiency and low-cost could become available to replace traditional crop growth lighting, in order to maximize the performance of STTPS.

\section{REFERENCES}

Awad, M. A., Wagenmakers, P. S., Jager, A. D. 2001. Effects of light on flavonoid and chlorogenic acid levels in the skin of 'Jonagold' apples. Sci. Hort. 88: 289-298.

Brown, C. S., Schuerger, A. C., Sager, J. C. 1995. Growth and photomorphogenesis of pepper plants under red light-emitting diodes with supplemental blue or far-red lighting. J. Am. Soc. Hort. Sci. 120: 808-813.

Cosgrove, D. J. 1981. Rapid suppression of growth by blue light. Plant Physiol. 67: 584-590.

Driever, S., Labrie, C., Verkerke, W. 2011. Increasing the level of vitamin C in tomato through light treatments during truss development. Wageningen UR Greenhouse Horticulture, 2011 Kick-off KBV Meeting, 2011-04-08.

Ebisawa, M., Shoji, K., Kato, M., Shimomura, K., Goto, F., Yoshihara, T. 2008. Supplementary ultraviolet radiation $\mathrm{B}$ together with blue light at night increased quercetin content and flavonol synthase gene expression in leaf lettuce (Lactuca sativa L.). Environ. Control Biol. 46: 1-11.

Gautier, H., Diakou-Verdin, V., Bénard, C., Reich, M., Buret, M., Bourgaud, F., Poëssel, J., Caris-Veyrat, C., Génard, M. 2008. How does tomato quality (sugar, acid, and nutritional quality) vary with ripening stage, temperature, and irradiance. J. Agric. Food Chem. 56: 1241-1250.

Gautier, H., Massot, C., Stevens, R., Sérino, S., Génard, M. 2009. Regulation of tomato fruit ascorbate content is more highly dependent on fruit irradiance than leaf irradiance. Ann. Bot. 103: 495-504.

Giacomelli, G. A., Ting, K. C., Mears, D. R. 1994. Design of a single truss tomato production system (STTPS). Acta Hort. 361: 77-84.

Goins, G. D. 2002. Growth, stomatal conductance, and leaf surface temperature of Swiss chard grown under diffenrent artificial lighting technologies. SAE Tech. Paper 2002-01-2338.

Goins, G. D., Yorio, N. C. 2000. Spinach growth and development under innovative narrow-and broadspectrum lighting sources. SAE Tech. Paper 2000-01-2290.

Goins, G. D., Yorio, N. C., Sanwo, M. M., Brown, C. S. 1997. Photomorphogenesis, photosynthesis, and seed yield of wheat plants grown under red light-emitting diodes (LEDs) with and without supplemental blue lighting. J. Expt. Bot. 48: 1407-1413.

Goto, E. 2003. Effects of light quality on growth of crop plants under artificial lighting. Environ. Control Biol. 41: 121-132.

Grimstad, S. O. 1987. Supplementary lighting of early tomatoes after planting out in glass and acrylic greenhouses. Sci. Hortic. 33: 189-196.

Hanyu, H., Shoji, K. 2000. Effects of blue light and red light on kidney bean plants grown under combined radiation from narrow-band light sources. Environ. Control Biol. 38: 13-24.

Hogewoning, S. W., Trouwborst, G., Maljaars, H., Poorter, H., Leperen, W. V., Harbinson, J. 2010. Blue light dose-responses of leaf photosynthesis, morphology, and chemical composition of Cucumis sativus grown under different combinations of red and blue light. J. Exp. Bot. 61: 3107-3117.

Hovi, T., Näkkilä, J., Tahvonen, R. 2004. Interlighting improves production of year-round cucumber. Sci. Hortic. 102: 283-294. 


\section{LIGHT QUALITY AND TOMATO}

Johkan, M., Shoji, K., Goto, F., Hashida, S., Yoshihara, T. 2010. Blue light-emitting diode light irradiation of seedlings improves seedling quality and growth after transplanting in red leaf lettuce. HortScience $\mathbf{4 5}$ : 1809-1814.

Johkan, M., Shoji, K., Goto, F., Hashida, S., Yoshihara, T. 2012. Effect of green light wavelength and intensity on photomorphogenesis and photosynthesis in Lactuca sativa. Environ. Exp. Bot. 75: 128-133.

Kim, H.-H. 2004. Green-light supplementation for enhanced lettuce growth under red- and blue-lightemitting diodes. HortScience 39: 1617-1622.

Klein, R. M. 1992. Effects of green light on biological systems. Biol. Rev. 67: 199-284.

Kobayashi, S. 1997. A study on single-truss tomato production by hydroponics. I. Plant growth and fruit yield by different sowing dates over the year. (in Japanese with English summary) J. Soc. Agr. Structures, Japan 27: 199-206.

Kobayashi, S. 1999. A study on single-truss tomato production by hydroponics. III. Effects of plant density and number of leaf above the truss on plant growth and fruit yield. (in Japanese with English summary) J. Soc. Agr. Structures, Japan 30: 53-60.

Kojima, M., Nakano, Y., Fujii, H. 2010. Light stimulation triggered expression of genes coding for vacuolar proton-pump enzymes V-ATPpase and V-PPase in buckwheat. Biosci. Biotechnol. Biochem. 74: 15071511.

Lefsrud, M. G. 2008. Irradiance from distinct wavelength light-emitting diodes affect secondary metabolites in kale. HortScience 43: 2243-2244.

Lester, G. E. 2006. Environmental regulation of human health nutrients (ascorbic acid, carotene, and folic acid) in fruits and vegetables. HortScience 41: 59-64.

Lu, N., Maruo, T., Johkan, M., Hohjo, M., Tsukagoshi, S., Ito, Y., Ichimura, T., Shinohara, Y. 2012. Effects of supplemental lighting within the canopy at different developing stages on tomato yield and quality of single-truss tomato plants grown at high density. Environ. Control Biol. 50: 1-11.

Massa, G. D., Kim, H.-H., Wheeler, R. M., Mitchell, C. A. 2008. Plant productivity in response to LED lighting. HortScience 43: 1951-1956.

McAvoy, R. J. 1984. Evaluation of a single flower cluster, high plant density greenhouse tomato crop system using high pressure sodium lights. Paper No. NAR84-405, ASAE, St. Joseph, MI 49085-9659, USA.

McAvoy, R. J., Janes, H. W. 1989. Tomato plant photosynthetic activity as related to canopy age and tomato development. J. Am. Soc. Hort. Sci. 114: 478-482.

McAvoy, R. J., Janes, H. W., Giacomelli, G. A., Giniger, M. S. 1989a. Validation of a computer model for a single truss tomato cropping system. J. Am. Soc. Hort. Sci. 114: 746-750.

McAvoy, R. J., Janes, H. W., Godfriaux, B. L., Secks, M., Duchai, D., Wittman, W. K. 1989b. The effect of total available photosynthetic photon flux on single truss tomato growth and production. J. Hortic. Sci. 64: 331-338.

Menard, C., Dorais, M., Hovi, T., Gosselin, A. 2006. Developmental and physiological responses of tomato and cucumber to additional blue light. Acta Hort. 711: 291-296.

Ohashi-Kaneko, K., Takase, M., Kon, N., Fujiwara, K., Kurata, K. 2007. Effect of light quality on growth and vegetable quality in leaf lettuce, spinach and komatsuna. Environ. Control Biol. 45: 189-198.

Okano, K., Nakano, Y., Watanabe, S.-I. 2001. Single-truss tomato system - a labor-saving management system for tomato production. JARQ 35: 177-184.

Pettersen, R. I., Torre, S., Gislerod, H. R. 2010. Effects of intracanopy lighting on photosynthetic characteristics in cucumber. Sci. Hort. 125: 77-81.

Rodriguez, B. P., Lambeth, V. N. 1975. Artificial lighting and spacing as photosynthetic and yield factors in winter greenhouse tomato culture. J. Am. Soc. Hort. Sci. 100: 694-697.

Samuoliene, G., Sirtautas, R., Brazaityte, A., Sakalauskaite, J., Sakalauskiene, S., Duchovskis, P. 2011. The impact of red and blue light-emitting diode illumination on radish physiological indices. Cent. Eur. J. Biol. 6: $821-828$.

Smith, H. 1993. Sensing the light environment: the functions of the phytochrome family. In "Photomorphogenesis in Plants" (ed. by Kendrick, R. E., Kronenberg, G. H. M.), Ed. 2. Kluwer Academic Publ., Dordrecht, p 377-416.

Stutte, G. W., Edney, S. 2009. Photoregulation of Bioprotectant content of red leaf lettuce with light-emitting diodes. HortScience 44: 79-82.

Terashima, I., Fujita, T., Inoue, T., Chow, W. S., Oguchi, R. 2009. Green light drives leaf photosynthesis more efficiently than red light in strong white light: revisiting the enigmatic question of why leaves are 


\section{N. LU ET AL.}

green. Plant Cell Physiol. 50: 684-697.

Ting, K. C., Giacomelli, G. A., Fang, W. 1993. Decision support system for single truss tomato production. XXV CIOSTA - CIGR V Congress, Wageningen, The Netherlands.

Yorio, N. C., Goins, G. D., Kagie, H. R., Wheeler, R. M., Sager. J. C. 2001. Improving spinach, radish, and lettuce growth under red light-emitting diodes (LEDs) with blue light supplementation. HortScience 36: 380-383. 